\title{
PAC1 receptor-deficient mice display impaired insulinotropic response to glucose and reduced glucose tolerance
}

\author{
Françoise Jamen, ${ }^{1}$ Kristin Persson, ${ }^{2}$ Gyslaine Bertrand, ${ }^{1}$ Nieves Rodriguez-Henche, ${ }^{1}$ \\ Raymond Puech, ${ }^{1}$ Joël Bockaert, ${ }^{1}$ Bo Ahrén, ${ }^{2}$ and Philippe Brabet ${ }^{1}$ \\ ${ }^{1}$ Unité Propre de Recherche (UPR 9023) Centre National de la Recherche Scientifique, Montpellier, France \\ ${ }^{2}$ Department of Medicine, Lund University, Malmö University Hospital, Malmö, Sweden \\ Address correspondence to: Philippe Brabet, UPR 9023 Centre National de la Recherche Scientifique, 141 rue de la Cardonille, \\ 34094 Montpellier Cedex 5, France. Phone: 33-4-67-14-29-64; Fax: 33-4-67-54-24-32; E-mail: brabet@bacchus.montp.inserm.fr.
}

Nieves Rodriguez-Henche's present address is: Departamento de Bioquímica y Biología Molecular, Universidad de Alcalá, Alcalá de Henares, Spain.

Received for publication January 17, 2000, and accepted in revised form March 28, 2000.

\begin{abstract}
Pituitary adenylate cyclase-activating polypeptide (PACAP) is a ubiquitous neuropeptide of the vasoactive intestinal peptide (VIP) family that potentiates glucose-stimulated insulin secretion. Pancreatic $\beta$ cells express two PACAP receptor subtypes, a PACAP-preferring (PAC1) and a VIP-shared (VPAC2) receptor. We have applied a gene targeting approach to create a mouse lacking the PAC1 receptor $\left(P A C 1^{-/}\right)$. These mice were viable and normoglycemic, but exhibited a slight feeding hyperinsulinemia. In vitro, in the isolated perfused pancreas, the insulin secretory response to PACAP was reduced by $50 \%$ in $\mathrm{PAC1}^{-/-}$mice, whereas the response to VIP was unaffected. In vivo, the insulinotropic action of PACAP was also acutely reduced, and the peptide induced impairment of glucose tolerance after an intravenous glucose injection. This demonstrates that PAC1 receptor is involved in the insulinotropic action of the peptide. Moreover, $P A C 1^{-/-}$mice exhibited reduced glucose-stimulated insulin secretion in vitro and in vivo, showing that the PAC1 receptor is required to maintain normal insulin secretory responsiveness to glucose. The defective insulinotropic action of glucose was associated with marked glucose intolerance after both intravenous and gastric glucose administration. Thus, these results are consistent with a physiological role for the PAC1 receptor in glucose homeostasis, notably during food intake.
\end{abstract}

J. Clin. Invest.105:1307-1315 (2000).

\section{Introduction}

The physiological function of pancreatic $\beta$ cells is to adapt the rate of insulin secretion to glycemia variations. Insulin release is finely tuned by a complex interplay between blood glucose (the major initiator) and incoming potentiators such as other nutrients, hormones, and neurotransmitters from the autonomic innervation (1). Peptides such as the vasoactive intestinal peptide (VIP), glucagon, and glucagon-like peptide-1 (GLP-1), belonging to the same family, participate in the physiological regulation of insulin secretion (2-4). More recently, pituitary adenylate cyclase-activating polypeptide (PACAP), a member of this family (5), has been demonstrated to potentiate the insulinotropic action of glucose in vitro both in isolated perfused rat pancreas (6-8) and in rat and mouse islets $(9,10)$, as well as in vivo in mice (11) and humans (12). PACAP exists mostly as a 38-residue peptide (PACAP38), but also as PACAP27, which consists of the $27 \mathrm{NH}_{2}$-terminal residues of PACAP38 (13). Both forms of PACAP potently stimulate insulin secretion with similar efficiency in mouse and rat islets (14). The peptide is ubiquitously distributed in central and peripheral nerve cells. PACAP-containing nerve fibers have been localized throughout the exocrine parenchyma and have been shown to innervate the intrapancreatic ganglia as well as the islets of Langerhans in mouse pancreas (15). Three types of high-affinity receptors for PACAP have been cloned: the PACAP-preferring type 1 (PAC1) and two VIP-shared type 2 (VPAC1 and VPAC2) receptors. PAC1 receptor has a much higher affinity for PACAP27 and PACAP38 than for VIP, whereas type 2 receptors recognize all peptides with equal high affinity. Both receptor subtypes are coupled to cAMP production (16-18). PACAP and VIP have been reported to be equipotent on insulin secretion in perfused rat pancreas, mouse islets, and insulinoma cells, suggesting the involvement of VPAC receptors $(8,14,19)$. However, Yada et al. (9) have reported that PACAP was more potent than was VIP in stimulating insulin release from rat islets, suggesting that PACAP-selective receptors are expressed in islet $\beta$ cells. Expression of mRNA encoding PAC1 and VPAC2 receptors has been detected in mouse and rat islets by in situ hybridization (14), and immunoreactivity for the PAC1 receptor has also been observed in rat islet cells (20). Together, these data indicate that PAC1 and VPAC2 receptors are expressed in insulin-producing cells. How- 
ever, the relative contribution of these PACAP receptor subtypes to endocrine function remains to be established. In mice, PACAP clearly stimulates insulin secretion, but also inhibits insulin sensitivity, as demonstrated by unaltered glucose disposal during an intravenous glucose tolerance test (11).

The aim of this study was to investigate the role of PAC1 receptors in insulin secretion and glucose disposal. A mouse strain deficient in PAC1 receptor $\left(\mathrm{PAC1}^{-/-}\right)$was generated by homologous recombination in embryonic stem cells. $P A C 1^{-/-}$mice were compared with wild-type counterparts for the effects of glucose and PACAP on insulin secretion and glucose tolerance. This work was performed both in vitro in isolated perfused pancreas, and in vivo.

\section{Methods}

PAC1 gene targeting. The intron-exon structure of the gene encoding the PAC1 receptor has already been elucidated (21). The gene was disrupted by deletion of a $2.3-\mathrm{kb} N c o$ I fragment containing exons 8-11, which was replaced by a pPolII-neomycin selection cassette in the reverse transcription orientation (22). The targeting vector contained $4.2 \mathrm{~kb}$ and $2.8 \mathrm{~kb}$ of homologous sequences up- and downstream from the pPolIIneomycin sequence, respectively. An MC1-TK counter selection marker flanked the $3^{\prime}$ homology (23). The linearized vector was electroporated into mouse embryonic stem cells (129/Sv-derived H1 embryonic stem cells from A. Dierich and P. Chambon, patent LGMEu184, Strasbourg, France). Targeted clones were screened for 2 weeks with $180 \mu \mathrm{g} / \mathrm{mL}$ geneticin (G418;
Life Technologies Inc., Gaithersburg, Maryland, USA) and $2 \mu \mathrm{M}$ ganciclovir (Cymevan; Syntex, Puteaux, France). DNA extracted from resistant clones was analyzed by Southern blotting with $5^{\prime}$ and $3^{\prime}$ flanking probes for homologous targeting events; five positive clones were confirmed by PCR analysis using primers p7 (5'-TGGGTTTGATGACTATGAGC-3'), p8 (5'TGAGGGTGACGAGGGAGG TG-3'), and pNeo (5'GCCTTCTATCGCCTTCTTGA-3'). Clones were injected into blastocysts to produce germline chimeras. An F1 crossbred mouse strain $(129 / \mathrm{Sv} \times \mathrm{C} 57 \mathrm{BL} 6 / \mathrm{J})$ heterozygous for loss of PAC1 was bred to yield wild-type mice and mutants heterozygous and homozygous for loss of the PAC1 receptor (PAC1 ${ }^{+/-}$and $P A C 1^{-/-}$mice).

Binding experiments. Brain membranes were prepared as described previously (24). PACAP27 (Neosystem, Strasbourg, France) was iodinated by the iodogen method (21). Competitive binding was performed by incubating $50 \mu \mathrm{g}$ of total brain membrane proteins with $50 \mathrm{pM}^{125} \mathrm{I}-$ PACAP27 and increasing amounts of cold PACAP27 for 60 minutes at $25^{\circ} \mathrm{C}$. Experiments were done in triplicate using at least two distinct membrane preparations. Binding data were analyzed using EBDA-Ligand software (Elsevier Biosoft, Cambridge, United Kingdom).

Measurement of cAMP levels in cerebellar granule cells and pancreatic islets. Mice cerebellar granule neurons were prepared from 7- to 8-day-old pups by mechanical dissociation (25). Cells were plated at $3 \times 10^{5}$ cells per $\mathrm{cm}^{2}$ on poly-L-ornithine; assays for CAMP production were done with 7 -day cultures. Cells were incubated with $\left[2-{ }^{3} \mathrm{H}\right]$ adenine for 2 hours in serum-free medium, then with 100 $\mu \mathrm{M}$ Ro-20-1724 (Biochem, Meudon, France) for 10 min- a

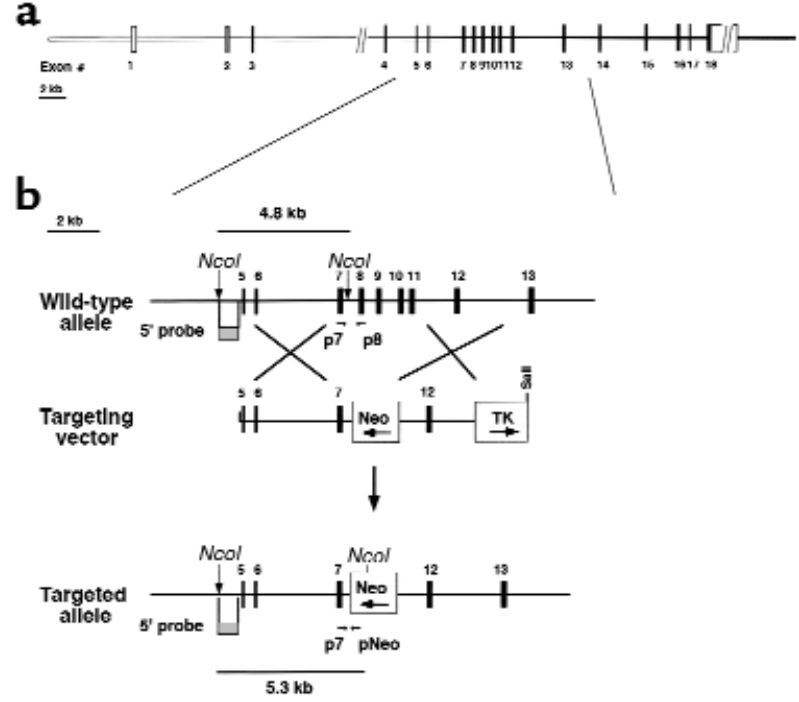

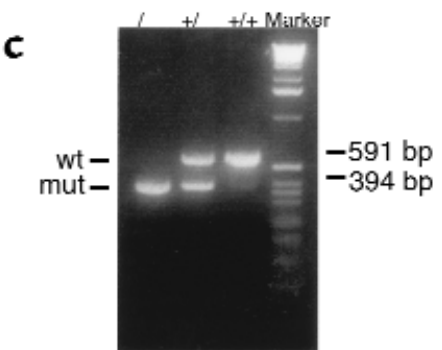

d

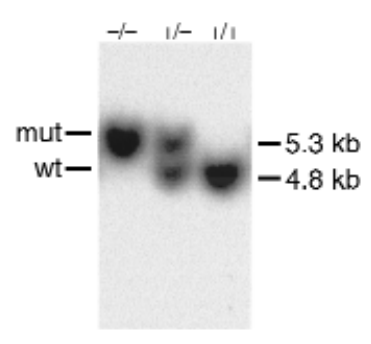

Figure 1

Genetic inactivation of the PAC1 gene. (a) Genomic organization of the mouse PAC1 receptor gene. Exons are represented by boxes, with open boxes for untranslated sequences and filled boxes for translated sequences. The numbers beneath indicate exon numbering. (b) Genomic structure of wild-type and targeted PAC1 alleles and the targeting vector. Primers ( 7 7, p8, and pNeo) used for PCR analysis, 5' probe used for Southern blot analysis, and expected Ncol restricted fragment sizes of the wild-type and mutated alleles are indicated. (c) PCR analysis of DNA from tail biopsies of wild-type mice, $P A C 1^{+/-}$mice, and $P A C 1^{-1-}$ mice. wt, wild-type; mut, mutant. (d) Southern blot analysis of the Ncol-digested DNA from tail biopsies of wild-type $\left(P A C 1^{+/+}\right)$mice, $P A C 1^{+/-}$mice, and $P A C 1^{-/-}$mice. 

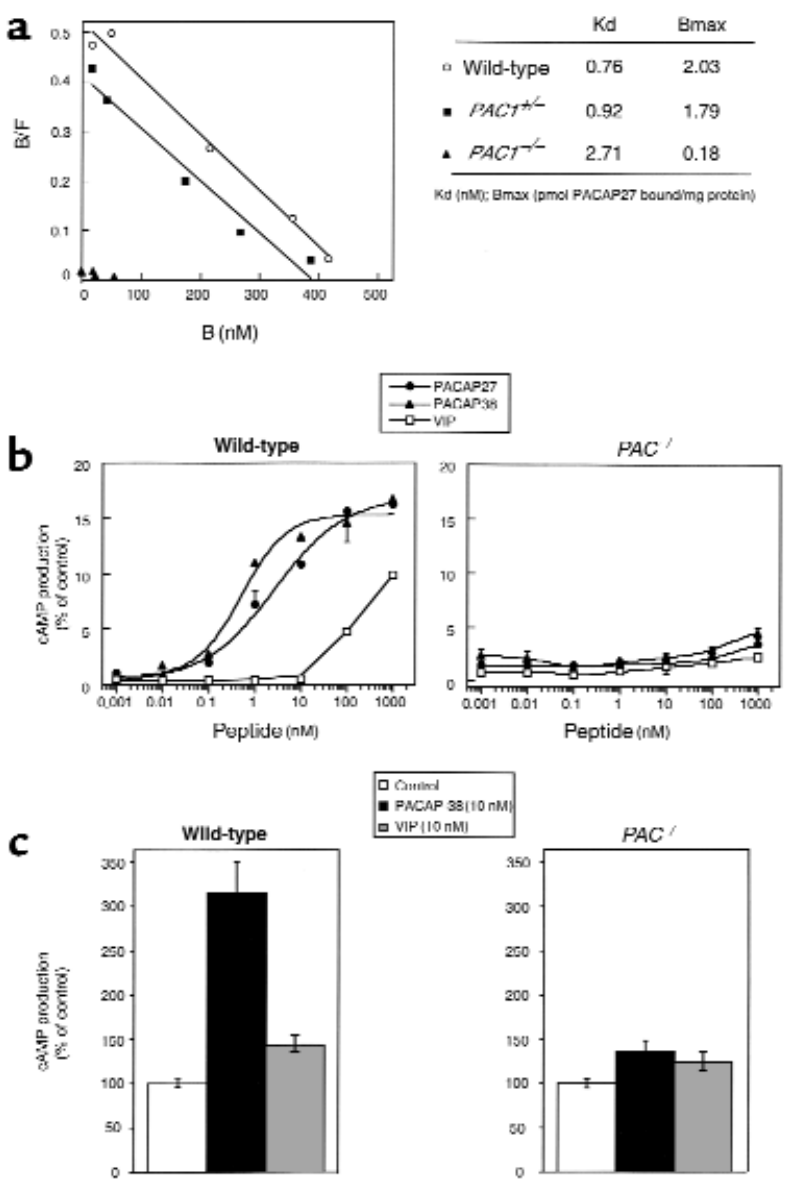

Figure 2

Absence of a functional PAC1 receptor. (a) Scatchard representation of ${ }^{125}$-PACAP27 binding on brain membranes from wild-type, $P A C 1^{+/-}$, and $P A C 1^{-1-}$ adult mice. (b) measurement of cAMP production in 7day cultures of cerebellar granule cells from 8-day-old pups after stimulation with PACAP27, PACAP38, or VIP. Data are expressed as the percentage of CAMP production induced by $100 \mathrm{nM}$ forskolin, and are the mean \pm SEM of at least three independent experiments performed in triplicate. (c) Measurement of cAMP production in freshly isolated pancreatic islets from adult mice after $16.7 \mathrm{mM}$ glucose alone (control), with PACAP38 or VIP stimulation. Data are expressed as a percentage of CAMP formation induced by glucose alone. Values are mean \pm SEM from at least five independent experiments. $B$, bound; $F$, free; $\mathrm{Kd}$, dissociation constant.

utes at $37^{\circ} \mathrm{C}$ followed by 15 minutes with PACAP27, PACAP38, or VIP (Neosystem). The islets were isolated by collagenase digestion of pancreas dissected from fed 30- to 32 -week-old female mice. After loading with $\left[2-{ }^{3} \mathrm{H}\right]$ adenine for 90 minutes in a medium containing $10 \mathrm{mM}$ glucose, they were incubated for 30 minutes in batches of 13-15 with $16.7 \mathrm{mM}$ glucose alone, and then for 15 minutes with PACAP38 or VIP in the presence of $250 \mu \mathrm{M}$ isobutyl methylxanthine. In both experiments, the reaction was stopped by $5 \%$ trichloracetic at $4^{\circ} \mathrm{C}$. After centrifugation, $\left[2-{ }^{3} \mathrm{H}\right] \mathrm{cAMP}$ was separated from $\left[2-{ }^{3} \mathrm{H}\right] \mathrm{ATP}$ and measured as described previously (26).

Plasma glucose and hormone measurements. Blood samples of conscious mice were drawn from the retrobulbar, intraorbital capillary plexus into heparinized chilled tubes, and were immediately centrifuged at $4^{\circ} \mathrm{C}$. Plasma was separated and then stored at $-20^{\circ} \mathrm{C}$ for subsequent determination of glucose, insulin, and glucagon levels. Plasma glucose levels were determined by the glucose oxidase method (Peridochrom Glucose; Roche Diagnostic Systems Inc., Indianapolis, Indiana, USA). Insulin and glucagon concentrations were determined by radioimmunoassay using charcoal separation as described previously (8).

Pancreatic insulin and glucagon content measurements. Whole pancreata were removed from the mice, and insulin and glucagon were extracted by mechanical homogenization in iced acid ethanol $(0.7 \mathrm{~mol} / \mathrm{L} \mathrm{HCl}-$ ethanol; 25:75). After 48 hours at $4^{\circ} \mathrm{C}$, hormone concentrations were determined by radioimmunoassay (8).

In vitro isolated perfused pancreas studies. Experiments were performed with female mice 21-30 weeks of age, fed ad libitum. After anesthesia with sodium pentobarbital (70 $\mathrm{mg} / \mathrm{kg}$ ), the pancreas was totally isolated from all neighboring tissues according to the surgical procedure for the rat pancreas described previously (27). The pancreas was then perfused through its own arterial system with KrebsRinger bicarbonate buffer. The preparation was maintained at $37.5^{\circ} \mathrm{C}$. Each organ was perfused at a constant flow rate of $1 \mathrm{~mL} / \mathrm{min}$ during a 30 -minute stabilization period. The flow rate was measured during 1 minute for each sample, which was immediately frozen for insulin determination. After each perfusion experiment, the pan-

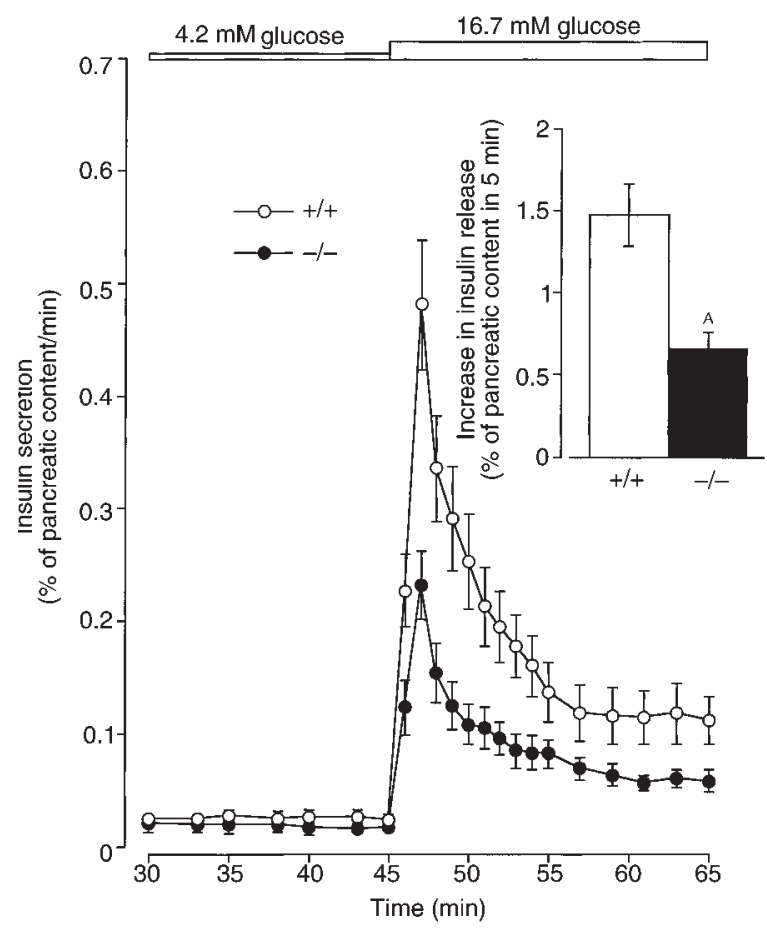

Figure 3

Insulin response to glucose in vitro. Effect of a glucose increase on insulin secretion from the isolated perfused pancreas of $P A C 1^{-/-}$and wild-type mice. Inset shows the increment of insulin output over the first 5 minutes of glucose stimulation. Values are expressed as mean $\pm \mathrm{SEM}, n=8$. ${ }^{\mathrm{A}} \mathrm{P}<0.001$. 

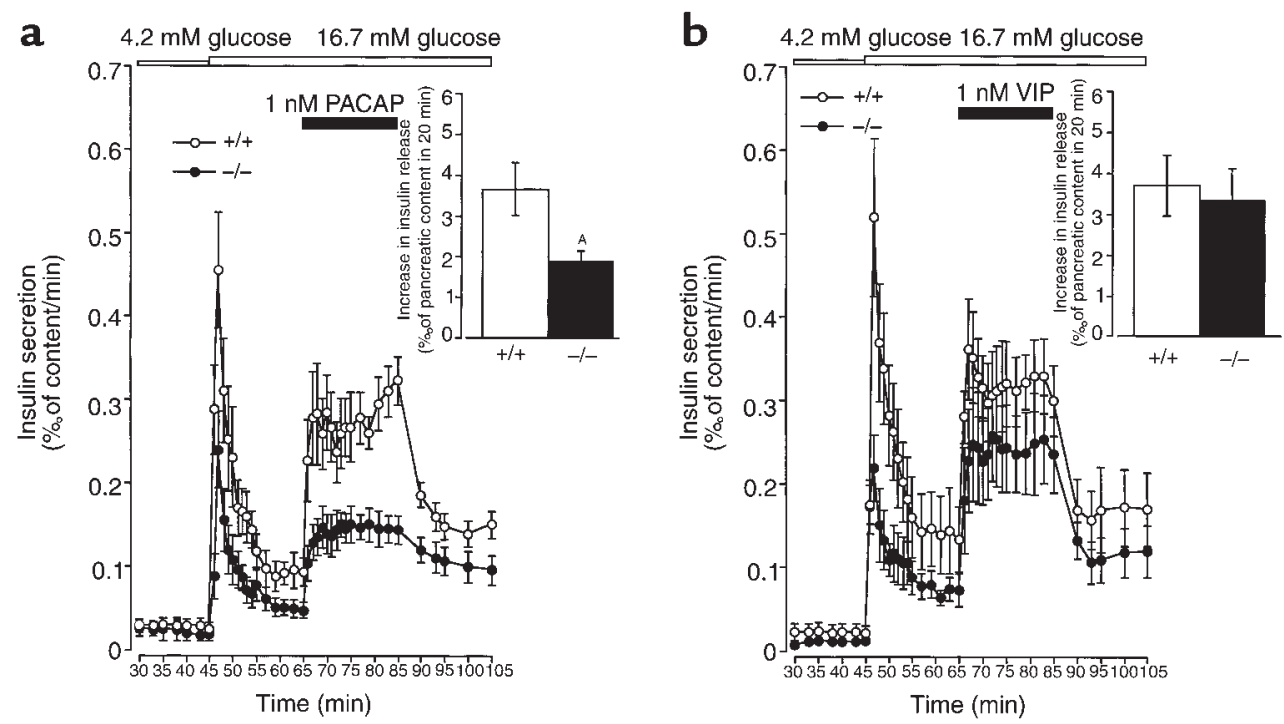

\section{Figure 4}

Insulin responses to PACAP and VIP in vitro. Effects of PACAP38 (a) or VIP (b) on $16.7 \mathrm{mmol} / \mathrm{L}$ glucose-induced insulin secretion from the isolated perfused pancreas of $P A C 1^{-1-}$ and wild-type mice. Insets show the increment of insulin output over the 20 minutes of peptide infusion. Values are expressed as mean $\pm \operatorname{SEM}(n=4-6)$. ${ }^{A} P<0.05$

creas insulin content was measured (8). For the kinetics of insulin output, results are expressed as changes in relation to the measured pancreatic insulin content.

Intravenous glucose tolerance test. Female mice fed ad libitum were anesthetized as described previously (11). D-glucose $(1 \mathrm{~g} / \mathrm{kg})$ was injected rapidly into a tail vein, either alone or together with PACAP27 or VIP. Both peptides were administered at $1.3 \mathrm{nmol} / \mathrm{kg}$, a dose that was shown to maximally activate insulin secretion when given intravenously in normal mice (11). In one series of experiments, L-arginine $(0.25$ $\mathrm{g} / \mathrm{kg}$ ) was injected. The volume load was $10 \mu \mathrm{L} / \mathrm{g}$ body wt. Blood samples were drawn into chilled heparinized tubes after 1, 5, 20, and 50 minutes from the retrobulbar, intraorbital capillary plexus. Plasma determinations of glucose and insulin were performed as described previously (11).

Gastric glucose tolerance test. Mice fasted for 2 hours were anesthetized as above. A blood sample was taken, and Dglucose $(150 \mathrm{mg} / \mathrm{mouse}$ in $0.5 \mathrm{~mL})$ was administered through a gavage tube placed in the stomach. Blood samples were thereafter taken at 10,30,60, and 120 minutes for plasma glucose and insulin determinations.

Data presentation and statistical analysis. Data are presented as mean \pm SEM. Statistical significance was assessed by Student's $t$ test for in vitro studies and by the nonparametric Mann-Whitney $U$ test for in vivo studies. Areas under the insulin and glucose curves $\left(\mathrm{AUC}_{\text {insulin }}\right.$ and $\mathrm{AUC}_{\text {glucose }}$ ) were calculated by the trapezoid rule.

\section{Results}

PAC1 receptor-deficient (PAC1 $\left.{ }^{-/}\right)$mice. An 18-exon gene (Figure 1a) encodes the mouse PAC1 receptor (21). To produce a null allele, we exchanged sequences in the targeting vector encoding exons 8-11 with a neomycin selection cassette (Figure 1b). After homologous recombination, analysis of genomic DNA was performed using Southern blot, PCR, or both (Figure 1, c and d) to distinguish the targeted allele from the wild type allele. The targeted allele harbors the neomycin cassette in an intronic region between exons 7 and 12, which is spliced out to generate a truncated mRNA that is detectable by RT-PCR analysis (data not shown). Moreover, this deletion leads to a frame shift with a translation stop codon in exon 12. Therefore, the mutated allele was expected to encode a null receptor. This was demonstrated by several things, including the loss of $90 \%$ of the ${ }^{125}$ I-PACAP 27 binding to $P A C 1^{-/}$mouse brain (Figure $2 \mathrm{a}$ ), a tissue that in the rat contains 10-fold more PACAP binding sites than VIP binding sites (28); and the absence of stimulation by PACAP and VIP of cAMP production in $P A C 1^{-/-}$cerebellar granule cells (Figure $2 \mathrm{~b}$, right panel). The wildtype counterparts displayed the pharmacological profile of the PAC1 receptor mediating cAMP production (Figure 2b, left panel). Additionally, there was a dramatic reduction of PACAP38-induced cAMP production in $P A C 1^{-/-}$pancreatic islets (Figure 2c), whereas the weak stimulating effect of VIP was not changed.

A mendelian distribution of pup genotypes from heterozygous mating was observed at birth. However, at weaning, a loss of $P A C 1^{-/-}$mice became very noticeable, with a genotype distribution of $9 \%, 59 \%$, and $32 \%$ for $P A C 1^{-/-}, P A C 1^{+/-}$, and wild-type mice, respectively (data not shown). This result indicated a $60 \%$ loss of $P A C 1^{-1-}$ pups $\left(\chi^{2}\right.$ test, $\left.P<0.005\right)$ during the 4 weeks after birth. This mortality remains to be explained. No significant death rate was observed thereafter.

Characteristics of $\mathrm{PAC1}^{-/-}$mice. This study was conducted on adult female mice $21-30$ weeks of age. Table 1 shows various measurements from wild-type and $P A C 1^{-/-}$mice. The latter exhibit a weak but significant 
decrease $(10 \%)$ in body weight. Whereas no significant difference was observed in either plasma glucose or plasma glucagon levels, a mild degree of hyperinsulinemia was recorded in conscious, fed $P A C 1^{-/-}$mice $(P$ $<0.05$ ). This effect was not observed in fasting conditions. Pancreatic insulin and glucagon were at comparable levels in $\mathrm{PAC1}^{-/-}$pancreas and wild-type pancreas. Thus, the PAC1 receptor did not appear to be essential for either proinsulin or glucagon biosynthesis.

\section{In vitro experiments}

Insulin response to glucose. To investigate the glucose sensitivity of $\beta$ cells in $P A C 1^{-/-}$mice, we measured the effect of increasing the glucose concentration from $4.2 \mathrm{mmol} / \mathrm{L}$ to $16.7 \mathrm{mmol} / \mathrm{L}$, on the insulin secretion from isolated perfused pancreas (Figure 3). The glucose stimulation induced an immediate and transient first phase of insulin release, followed by a constant second phase. $P A C 1^{-/-}$mice displayed a defective insulin response to glucose, particularly during the first phase, when the increment of insulin output over the first 5 minutes was reduced by $55 \%$ $(P<0.001)$ compared with wild-type mice (Figure 3 , inset).

Effects of PACAP and VIP on glucose-induced insulin release. PACAP38 and VIP insulinotropic effects were evaluated from isolated pancreas perfused for 20 minutes with high glucose (Figure 4). In the presence of $16.7 \mathrm{mmol} / \mathrm{L}$ glucose, $1 \mathrm{nM}$ PACAP38 potentiated insulin secretion, but this effect was about twofold lower in $P A C 1^{-/-}$mice than in wild-type controls. The increment of insulin output
Table 1

Baseline value characteristics of conscious wild-type and $P A C 1^{-1-}$ mice, fed ad libitum or fasted for 24 hours

\begin{tabular}{|c|c|c|}
\hline Genotype & $+/+$ & $-1-$ \\
\hline Body weight (g) & $\begin{array}{c}30.94 \pm 0.89 \\
(n=15)\end{array}$ & $\begin{array}{c}28.66 \pm 0.68 \\
(n=17)^{\mathrm{A}}\end{array}$ \\
\hline Plasma concentration & $n=16$ & $n=14$ \\
\hline $\begin{array}{l}\text { Glucose }(\mathrm{mmol} / \mathrm{L}) \\
\text { Fasted } \\
\text { Fed }\end{array}$ & $\begin{array}{l}3.77 \pm 0.22 \\
7.94 \pm 0.28\end{array}$ & $\begin{array}{l}3.33 \pm 0.22 \\
8.11 \pm 0.28\end{array}$ \\
\hline $\begin{array}{l}\text { Insulin }(\mathrm{pmol} / \mathrm{L}) \\
\text { Fasted } \\
\text { Fed }\end{array}$ & $\begin{array}{c}63.7 \pm 8.4 \\
125.6 \pm 20.1\end{array}$ & $\begin{array}{c}55.3 \pm 15.1 \\
211.1 \pm 35.2^{\mathrm{A}}\end{array}$ \\
\hline $\begin{array}{l}\text { Glucagon }(\mathrm{pmol} / \mathrm{L}) \\
\text { Fasted } \\
\text { Fed }\end{array}$ & $\begin{array}{l}62.9 \pm 4.8 \\
61.2 \pm 4.7\end{array}$ & $\begin{array}{l}72.5 \pm 6.7 \\
66.8 \pm 6.9\end{array}$ \\
\hline Pancreatic contents & $n=15$ & $n=17$ \\
\hline $\begin{array}{l}\text { Protein (mg/pancreas) } \\
\text { Insulin }(\mu \mathrm{g} / \mathrm{mg} \text { protein }) \\
\text { Glucagon }(\mu \mathrm{g} / \text { mg protein })\end{array}$ & $\begin{array}{c}18.16 \pm 1.29 \\
1.740 \pm 0.169 \\
0.0437 \pm 0.003\end{array}$ & $\begin{aligned} 15.68 & \pm 1.58 \\
1.632 & \pm 0.124 \\
0.0493 & \pm 0.004\end{aligned}$ \\
\hline
\end{tabular}

Assays were performed with 20- to 30-week-old mice. ${ }^{A}$ Significantly different from wild-type $(+/+)$ mice, $P<0.05$. Values are mean \pm SEM; $n$, number of mice.

over 20 minutes of peptide infusion was $1.887 \pm 0.264 \%$ and $3.655 \pm 0.646 \%$ o $(P<0.05)$ of total pancreatic content in $P A C 1^{-/-}$and wild-type mice, respectively (Figure $4 a$, inset). In contrast, $1 \mathrm{nM}$ VIP elicited a comparable increase in insulin secretion in $P A C 1^{-/}$and control pancreas $(3.322 \pm 0.808 \%$ and $3.716 \pm 0.740 \%$ of content;
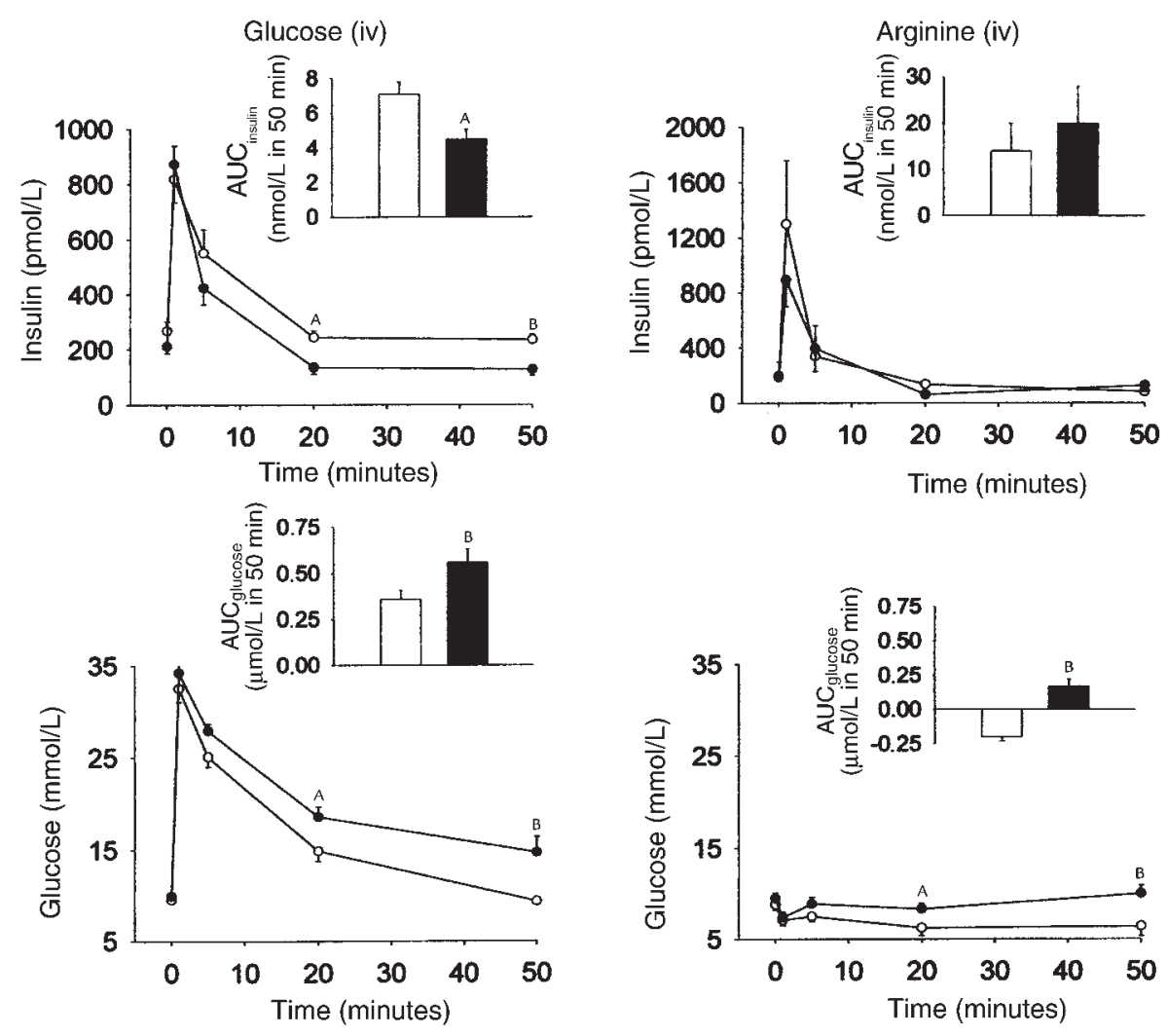

Figure 5

Intravenous glucose tolerance test. Plasma insulin and glucose levels immediately before and after an intravenous injection of glucose $(1 \mathrm{~g} / \mathrm{kg})$ or arginine $(0.25 \mathrm{~g} / \mathrm{kg})$ in anesthetized wild-type mice ( $n=27$ in left panel; $n=7$ in right panel) and $P A C 1^{-1-}$ mice $(n=$ 24 in left panel; $n=7$ in right panel). Insets are $\mathrm{AUC}_{\text {insulin }}$ and $A \cup C_{\text {glucose }}$ during the 50 minutes after glucose or arginine injection in wild-type mice (open bars) and in $\mathrm{PAC1}^{-/-}$ mice (filled bars). Data presented as mean \pm SEM. ${ }^{A} P<$ 0.05 ; ${ }^{\mathrm{B}} P<0.01$. iv, intravenous. 

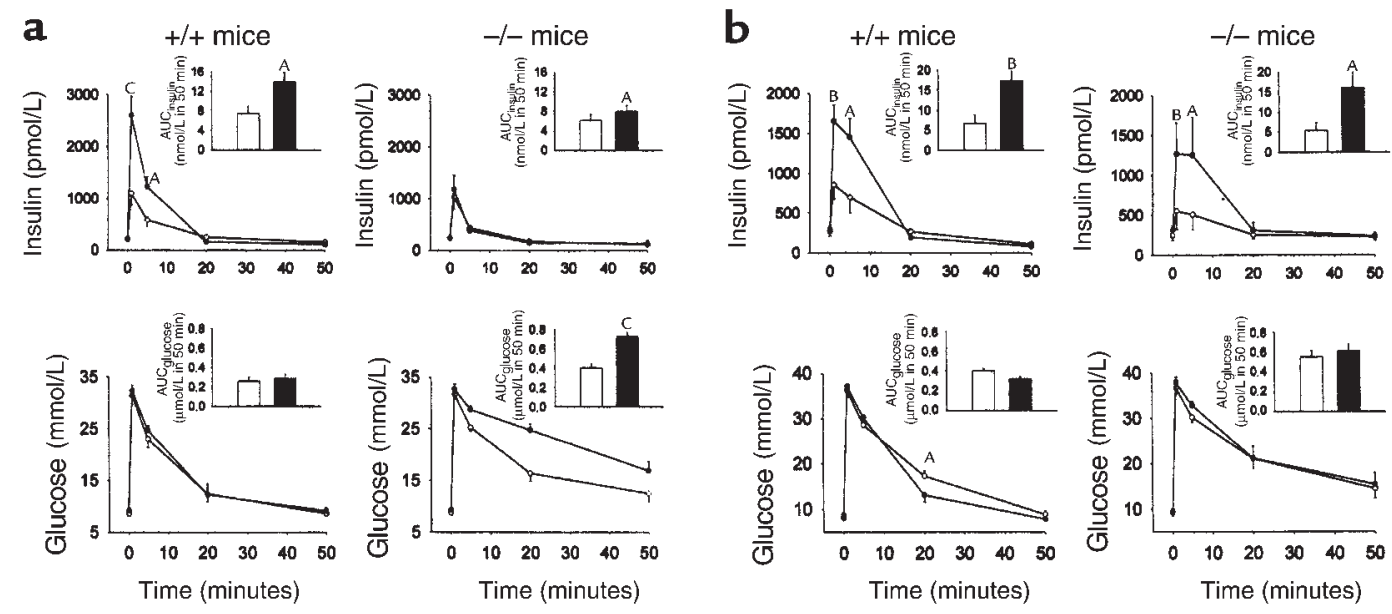

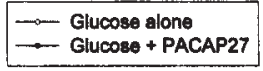

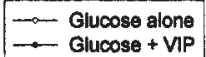

\section{Figure 6}

Effects of intravenous PACAP and VIP on glucose-induced insulin secretion and glucose disappearance. Plasma insulin and glucose levels immediately before and after an intravenous injection of $1 \mathrm{~g} / \mathrm{kg}$ glucose alone $(n=9-11$ in $\mathbf{a}$ and $n=5-7$ in $\mathbf{b})$, glucose with $1.3 \mathrm{nmol} / \mathrm{kg}$ PACAP27 (a, $n=10-11)$, or glucose with $1.3 \mathrm{nmol} / \mathrm{kg}$ VIP $(\mathbf{b}, n=6-7)$ in anesthetized wild-type mice and PAC1 $1^{-/-}$mice. Insets show $A \cup C_{\text {insulin }}$ and $A \cup C_{\text {glucose }}$ during the 50 minutes after administration of glucose alone (open bars), glucose with PACAP27 (filled bars in a), or glucose with VIP (filled bars in $\mathbf{b}$ ) in wild-type and $P A C 1^{-1-}$ mice. Data are presented as mean \pm SEM. ${ }^{A} P<0.05 ;{ }^{B} P<0.01 ;{ }^{C} P<0.001$.

Figure $4 \mathrm{~b}$, inset). We and others $(8,29)$ have previously reported that PACAP and VIP exert a vasodilator effect in the rat whole pancreas by activating VPAC receptors. Both PACAP and VIP elicited a progressive and sustained increase in pancreatic flow rate in a similar manner in $P A C 1^{-/-}$and wild-type pancreas (data not shown), supporting that VPAC receptors are intact in $P A C 1^{-/-}$mice. In vivo experiments

Intravenous glucose tolerance test. In anesthetized $P A C 1^{-/-}$ mice, after an intravenous injection of glucose $(1 \mathrm{~g} / \mathrm{kg})$, glucose tolerance and insulin response were significantly impaired (Figure 5, left panel). Within 1 minute, the plasma insulin response to glucose was not significantly different among the groups of mice, but the 20minute $(P<0.05)$ and 50 -minute $(P<0.01)$ insulin levels, as well as the 50 -minute $\mathrm{AUC}_{\text {insulin }}(P<0.05)$ were significantly lower in $\mathrm{PAC1}^{-/-}$mice than in wild-type mice. Simultaneously, the glucose elimination rate was decreased in $P A C 1^{-1-}$ mice. Thus, the $20-(P<0.05)$ and 50 -minute $(P<0.01)$ glucose levels and the 50 -minute $\operatorname{AUC}_{\text {glucose }}(P<0.01)$ were significantly higher in $P A C 1^{-1-}$ mice than in wild-type mice (Figure 5, left panel, inset). The impaired insulin response to glucose was also evident when comparing the insulin and glucose data at different timepoints, because the insulinogenic index (the insulin level divided by the glucose level) was lower in $P A C 1^{-/-}$mice than in wild-type mice both at $20 \mathrm{~min}$ utes $(7.6 \pm 0.3 \mathrm{pmol} / \mathrm{mmol}$ vs. $17.7 \pm 1.2 \mathrm{pmol} / \mathrm{mmol}, P$ $<0.01)$ and 50 minutes $(8.8 \pm 0.6 \mathrm{pmol} / \mathrm{mmol}$ vs. $26.4 \pm$ $1.9 \mathrm{pmol} / \mathrm{mmol}, P<0.001)$.

In contrast to the impaired insulin response to glucose, the increase in plasma insulin after intravenous administration of arginine was not significantly different between wild-type and $P A C 1^{-/-}$mice (Figure 5, right panel). However, the plasma glucose levels at 20 $(P<0.05)$ and $50(P<0.01)$ minutes and 50 -minute $\mathrm{AUC}_{\text {glucose }}(P<0.01)$ were significantly higher in $P A C 1^{-/-}$mice than in wild-type mice.

Insulin and glucose responses to intravenous PACAP and VIP during an intravenous glucose tolerance test. When PACAP27 $(1.3 \mathrm{nmol} / \mathrm{kg})$ was administered intravenously together with glucose, a marked increase of plasma insulin was observed in wild-type mice without any discernible effect on the glucose elimination rate (Figure 6a, left panel). In PAC1 ${ }^{-/-}$mice, however, PACAP27 not only potentiated glucose-induced insulin secretion just slightly, but also clearly decreased the glucose elimination rate (Figure 6a, right panel). Thus, the 50-minute $\mathrm{AUC}_{\text {glucose }}$ with PACAP27 stimulation was $0.29 \pm 0.04 \mu \mathrm{mol} / \mathrm{L}$ in wild-type mice vs. $0.72 \pm 0.05 \mu \mathrm{mol} / \mathrm{L}$ in $P A C 1^{-/-}$mice $(P<0.001)$. In contrast, VIP at the same dose $(1.3 \mathrm{nmol} / \mathrm{kg})$ exerted a similar stimulatory effect on insulin secretion in $P A C 1^{-/}$and wild-type mice (Figure 6b). However, whereas VIP slightly raised the glucose elimination rate in wild-type mice (the 20 -minute glucose value was $17.3 \pm 1.2 \mathrm{mmol} / \mathrm{L}$ in controls vs. $13.5 \pm 1.5$ $\mathrm{mmol} / \mathrm{L}$ after administration of VIP, $P<0.05$ ), it did not improve the impaired glucose elimination in PAC1 ${ }^{-1-}$ mice.

Gastric glucose tolerance test. Administration of glucose $(150 \mathrm{mg} /$ mouse) through a gastric tube raised insulin and glucose plasma levels in both wild-type and $\mathrm{PAC1}^{-/-}$mice (Figure 7). Peak insulin levels were observed at 30 minutes after glucose administration. 
This glucose-induced insulin increase was markedly reduced in $P A C 1^{-/-}$mice, both at 10 minutes $(P<0.05)$ and 30 minutes $(P<0.01)$. The 120 -minute $\mathrm{AUC}_{\text {insulin }}$ was $44 \%$ lower in $P A C 1^{-/-}$mice than in wild-type mice $(P<0.001)$. Furthermore, $P A C 1^{-1-}$ mice were markedly glucose intolerant compared with wild-type mice, as judged from elevated 60-minute $(P<0.001)$ and 120 minute $(P<0.01)$ glucose levels, and a 55\% higher 120 minute $\mathrm{AUC}_{\text {glucose }}(P<0.01)$.

\section{Discussion}

In this study, we explored a role for the PACAP-preferring receptor, PAC1, in the regulation of insulin secretion and glucose homeostasis using mice lacking this receptor. PAC1 receptor deletion resulted in a decrease of PACAP-induced insulin secretion, clearly demonstrating the functional involvement of this receptor in the insulinotropic action of the peptide. More interestingly, these mice exhibited an impairment of glucose-induced insulin secretion and a reduction in glucose tolerance. This suggests that the presence of the PAC1 receptor is required to maintain normal insulin secretory responsiveness to glucose and glucose homeostasis.

Both PAC1 and VPAC2 receptors are expressed in mouse islets (14). These two receptor subtypes show equal affinity for PACAP, but VIP activates only the VPAC2 receptor (17). Therefore, our previous findings that PACAP27, PACAP38, and VIP were equipotent in stimulating insulin secretion $(8,14)$ suggested that the VPAC2 receptor had the most functional importance for the PACAP insulin secretory effect. However, in the isolated perfused pancreas of $\mathrm{PAC1}^{-/-}$mice, the insulin secretory response to PACAP was reduced by about twofold. This decrease in responsiveness of PACAP in $P A C 1^{-/-}$mice is probably not related to a change in pancreatic blood flow, because similar vasodilatory responses to PACAP were recorded in $P A C 1^{--}$and wild-type mice. Moreover, this decrease was not associated with a reduction in pancreatic insulin content. In contrast, in $\mathrm{PAC1}^{-/-}$mice and wild-type mice, VIP potentiated glucose-induced insulin secretion to the same extent. Therefore, these results suggest that PAC1 receptors are quite important for PACAP-induced insulin secretion, and that the remaining insulinotropic action of PACAP observed in vitro in $\mathrm{PAC1}^{-/-}$pancreas is caused by activation of VPAC2 receptors, which are intact in these mice.

In the isolated perfused pancreas and in vivo, $P A C 1^{-/-}$ mice exhibited a defect in glucose-stimulated insulin release. Two recent studies have reported the inhibition of glucose-stimulated insulin secretion by immunoneutralization of PACAP in freshly isolated rat and mouse islets $(10,20)$, suggesting that endogenous PACAP contributes to the insulin secretory response to glucose. Therefore, our data support and extend these previous reports by providing evidence for the involvement of PAC1 receptors in the insulinotropic action of glucose. Moreover, in contrast to glucose, the insulin response to arginine was not impaired in $\mathrm{PAC1}^{-/-}$mice, showing that the dependence of insulin secretion on the PAC1 receptor is restricted to glucose stimulation and is not a general phenomenon. Although the mechanisms explaining this dependence remain to be studied, one possible explanation could be the fact that cAMP is required for the action of glucose (30). It is indeed known that PACAP, like the intestinal hormone GLP-1, augments the formation of $\operatorname{cAMP}(19,31)$ and increases the glucose competence of pancreatic $\beta$ cells (32). The strong reduction of islet cAMP production by $\mathrm{PACAP}$ in $\mathrm{PAC1}^{-/-}$mice might be a factor in impaired glucose sensing.

The defect in glucose-induced insulin secretion was associated with impaired glucose tolerance in $\mathrm{PAC1}^{-/-}$ mice, consistent with a role for PAC1 in the control of glucose homeostasis. However, these mice exhibit normal glycemia in both the fasted and fed states. Glucose homeostasis results from a balance between insulin secretion and peripheral tissue sensitivity to insulin, although insulin-independent mechanisms also contribute. Because the fed conscious $P A C 1^{-/}$mice had higher insulin levels than wild-type mice, it seems possible that, in addition to the defect in insulin secretion, insulin resistance may also participate in the glucose intolerance. In this context, it has been reported that PAC1 receptors are expressed in adipose tissues $(33,34)$,
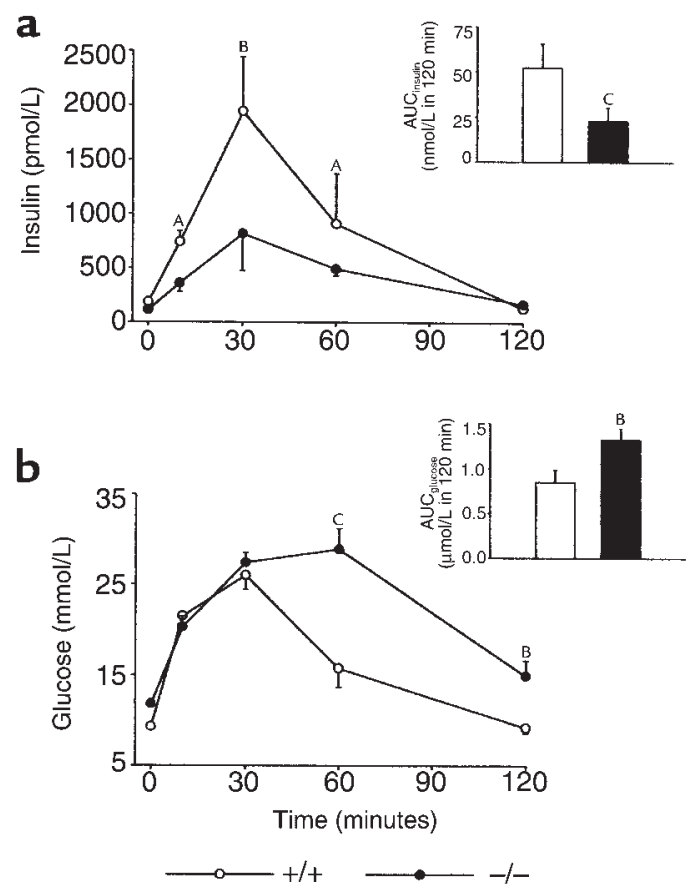

Figure 7

Gastric glucose tolerance test. Plasma insulin (a) and glucose (b) immediately before and at 10,30,60, and 120 minutes after gastric administration of glucose ( $150 \mathrm{mg} / \mathrm{mouse})$ in 2-hour fasted anesthetized wild-type mice $(n=12)$ and PAC1 ${ }^{-1-}$ mice $(n=12)$. Insets are 120-minute $A \cup C_{\text {insulin }}$ and $A \cup C_{\text {glucose }}$ (areas under the 120-minute insulin and glucose curves, respectively), in wild-type mice (open bars) and in $P A C 1^{-1-}$ mice (filled bars). Data are presented as mean \pm SEM. ${ }^{A} P<0.05 ;{ }^{B} P<0.01 ;{ }^{C} P<0.001$. 
and that PACAP potentiates insulin-stimulated glucose uptake in 3T3 L1 adipocytes (34). On the other hand, a previous study in normal mice showed that during an intravenous glucose tolerance test, PACAP, despite its potent insulinotropic action, did not increase glucose elimination (11). Although the mechanism of this action remains to be elucidated, the inhibition of insulin sensitivity by PACAP was thought to be mediated by adrenaline, which is released by PACAP from the adrenal medulla and is known to inhibit insulin action. In our study, the absence of any effect of PACAP on glucose disposal was also observed in wild-type mice, and the peptide was found to induce glucose intolerance in $\mathrm{PAC1}^{-/-}$mice. This suggests that under in vivo conditions, PACAP counteracts the action of insulin on glucose elimination. The induction of glucose intolerance by PACAP in $P A C 1^{-1-}$ mice may therefore result not only from the defect of the insulinotropic action of the peptide, but also from VPAC receptor activation stimulating glucagon release from pancreatic A cells (8) and hepatic glycogenolysis $(35,36)$, actions that counteract those of insulin. This is supported by the fact that VIP did not improve glucose tolerance despite its insulinotropic action, preserved in $\mathrm{PAC1}^{-/-}$mice. However, it must be noted that PACAP was unable to increase plasma glucagon in the presence of high glucose levels during a glucose tolerance test (11). Taken together, these data support the view that PACAP, by activating either PAC1 or VPAC receptors, in addition to its insulinotropic action, could also regulate glucose homeostasis in a complex manner that remains to be fully elucidated.

The impaired insulin secretion and glucose tolerance in $P A C 1^{-/-}$mice that was recorded after gastric administration of glucose emphasize the physiological importance of the PAC1 receptor for insulin secretion and glycemia control, and suggest its involvement during food intake. This supports a recent demonstration that the PACAP receptor antagonist, $\mathrm{PACAP}(6-27)$, inhibits the insulin response to gastric glucose in mice (37), and further suggests that this action is in part mediated by PAC1 receptors. It is known that during the cephalic and intestinal phases of food intake, the parasympathetic nerves supplying pancreatic islets participate in prandial insulin secretion (38). Because PACAP is known to be localized in the islet parasympathetic nerves (15) and released during vagus stimulation (39), our findings suggest that this neuropeptide, through PAC1 receptor activation, could be involved in the parasympathetic control of insulin secretion during food intake.

In conclusion, our data demonstrate, under physiological conditions, that PAC1 receptors are (a) responsible for the insulinotropic action of PACAP in addition to VPAC receptors; (b) involved in the glucose competence of pancreatic $\beta$ cells; and (c) participate in the control of glucose homeostasis, notably during food intake. $\mathrm{PAC1}^{-/-}$ mice should therefore represent an animal model that may be used to precisely determine the pharmacological role of this family of PACAP/VIP receptors in the regulation of insulin secretion and glucose homeostasis. Fur- thermore, this may be particularly useful for predicting specific drug actions. Because PACAP is present in pancreas and stimulates insulin secretion in humans (12), it is tempting to speculate that a dysfunction of the PAC1 receptor, associated with a defect of glucose-stimulated insulin secretion and glucose intolerance, may be relevant to the development of the pathogenesis in human noninsulin-dependent diabetes mellitus.

\section{Acknowledgments}

The authors would like to thank A. Dierich and P. Chambon for providing the embryonic stem cells. We are grateful to L. Journot for his help in the project, A. Cohen-Solal, P. Minary, A. Delalbre, G. Fauconnier, L. Kvist, L. Bengtsson, and U. Gustavsson for expert technical assistance, and A. Turner-Madeuf and L. Charvet for manuscript preparation. The study was supported by the Centre National de la Recherche Scientifique, the Institut National de la Santé et la Recherche Médicale, the European Commission (BIO-98-0517), the Swedish Medical Research Council (14X-6834), E. Lundström, A. Påhlsson, the Crafoord Foundation, Novo Nordisk Foundation, the Swedish Diabetes Association, Malmö University Hospital, and the Faculty of Medicine, Lund University.

1. Henquin, J.C. 1994. Cell biology of insulin secretion. In Joslin's diabetes mellitus. 13th edition. C.R. Kahn, and G.C. Weir, editors. Lea \& Febiger. Philadelphia, Pennsylvania, USA. 56-80.

2. Schebalin, M., Said, S.I., and Makhlouf, G.M. 1977. Stimulation of insulin and glucagon secretion by vasoactive intestinal peptide. Am.J. Physiol. 232:E197-E200.

3. Pipeleers, D., in't Veld, P.I., Maes, E., and Van De Winkel, M. 1982. Glucose-induced insulin release depends on functional cooperation between islet cells. Proc. Natl. Acad. Sci. USA. 79:7322-7325.

4. Ahren, B. 1998. Glucagon-like peptide-1 (GLP-1): a gut hormone of potential interest in the treatment of diabetes. Bioessays. 20:642-651.

5. Miyata, A., et al. 1989. Isolation of a novel 38 residue-hypothalamic polypeptide which stimulates adenylate cyclase in pituitary cells. Biochem. Biophys. Res. Commun. 164:567-574.

6. Kawai, K., et al. 1992. Pituitary adenylate cyclase activating polypeptide stimulates insulin release from the isolated perfused rat pancreas. Life Sci. 50:257-261.

7. Yokota, C., et al. 1993. Stimulatory effects of pituitary adenylate cyclaseactivating polypeptide (PACAP) on insulin and glucagon release from the isolated perfused rat pancreas. Acta Endocrinol. (Copenh.)129:473-479.

8. Bertrand, G., Puech, R., Maisonnasse, Y., Bockaert, J., and LoubatieresMariani, M.M. 1996. Comparative effects of PACAP and VIP on pancreatic endocrine secretions and vascular resistance in rat. Br.J. Pharmacol. 117:764-770.

9. Yada, T., et al. 1994. Pituitary adenylate cyclase activating polypeptide is an extraordinarily potent intra-pancreatic regulator of insulin secretion from islet beta-cells. J. Biol. Chem. 269:1290-1293.

10. Filipsson, K., Sundler, F., and Ahren, B. 1999. PACAP is an islet neuropeptide which contributes to glucose-stimulated insulin secretion. Biochem. Biophys. Res. Commun. 256:664-667.

11. Filipsson, K., Pacini, G., Scheurink, A.J., and Ahren, B. 1998. PACAP stimulates insulin secretion but inhibits insulin sensitivity in mice. Am.J. Physiol. 274:E834-E842.

12. Filipsson, K., Tornoe, K., Holst, J., and Ahren, B. 1997. Pituitary adenylate cyclase-activating polypeptide stimulates insulin and glucagon secretion in humans. J. Clin. Endocrinol. Metab. 82:3093-3098.

13. Miyata, A., et al. 1990. Isolation of a neuropeptide corresponding to the $\mathrm{N}$-terminal 27 residues of the pituitary adenylate cyclase activating polypeptide with 38 residues (PACAP38). Biochem. Biophys. Res. Commun. 170:643-648.

14. Filipsson, K., Sundler, F., Hannibal, J., and Ahren, B. 1998. PACAP and PACAP receptors in insulin producing tissues: localization and effects. Regul. Pept. 74:167-175.

15. Fridolf, T., Sundler, F., and Ahren, B. 1992. Pituitary adenylate cyclaseactivating polypeptide (PACAP): occurrence in rodent pancreas and 
effects on insulin and glucagon secretion in the mouse. Cell Tissue Res. 269:275-279.

16. Spengler, D., et al. 1993. Differential signal transduction by five splice variants of the PACAP receptor. Nature. 365:170-175.

17. Arimura, A., and Shioda, S. 1995. Pituitary adenylate cyclase activating polypeptide (PACAP) and its receptors: neuroendocrine and endocrine interaction. Front. Neuroendocrinol. 16:53-88.

18. Harmar, A.J., et al. 1998. International Union of Pharmacology. XVIII. Nomenclature of receptors for vasoactive intestinal peptide and pituitary adenylate cyclase-activating polypeptide. Pharmacol. Rev. 50:265-270.

19. Straub, S.G., and Sharp, G.W. 1996. A wortmannin-sensitive signal transduction pathway is involved in the stimulation of insulin release by vasoactive intestinal polypeptide and pituitary adenylate cyclase-activating polypeptide. J. Biol. Chem. 271:1660-1668.

20. Yada, T., et al. 1997. Pituitary adenylate cyclase-activating polypeptide (PACAP) is an islet substance serving as an intra-islet amplifier of glucose-induced insulin secretion in rats. J. Physiol. (Lond.) 505:319-328.

21. Pantaloni, C., et al. 1996. Alternative splicing in the N-terminal extracellular domain of the pituitary adenylate cyclase-activating polypeptide (PACAP) receptor modulates receptor selectivity and relative potencies of PACAP-27 and PACAP-38 in phospholipase C activation. J. Biol. Chem. 271:22146-22151.

22. Soriano, P., Montgomery, C., Geske, R., and Bradley, A. 1991. Targeted disruption of the c-src proto-oncogene leads to osteopetrosis in mice. Cell. 64:693-702.

23. Mansour, S.L., Thomas, K.R., and Capecchi, M.R. 1988. Disruption of the proto-oncogene int- 2 in mouse embryo-derived stem cells: a general strategy for targeting mutations to non-selectable genes. Nature. 336:348-352.

24. Shivers, B.D., Gorcs, T.J., Gottschall, P.E., and Arimura, A. 1991. Two high affinity binding sites for pituitary adenylate cyclase-activating polypeptide have different tissue distributions. Endocrinology. 128:3055-3065.

25. Lafon-Cazal, M., et al. 1999. mGluR7-like metabotropic glutamate receptors inhibit NMDA-mediated excitotoxicity in cultured mouse cerebellar granule neurons. Eur. J. Neurosci. 11:663-672.

26. Salomon, Y., Londos, C., and Rodbell, M. 1974. A highly sensitive adenylate cyclase assay. Anal. Biochem. 58:541-548.

27. Bertrand, G., Chapal, J., and Loubatieres-Mariani, M.M. 1986. Potenti- ating synergism between adenosine diphosphate or triphosphate and acetylcholine on insulin secretion. Am. J. Physiol. 251:E416-E421.

28. Masuo, Y., Ohtaki, T., Masuda, Y., Tsuda, M., and Fujino, M. 1992. Binding sites for pituitary adenylate cyclase activating polypeptide (PACAP): comparison with vasoactive intestinal polypeptide (VIP) binding site localization in rat brain sections. Brain Res. 575:113-123.

29. Carlsson, P.O., Ostenson, C.G., Efendic, S., Langel, U., and Jansson, L. 1996. Pituitary adenylate cyclase activating polypeptide (PACAP) redistributes the blood within the pancreas of anesthetized rats. Regul. Pept. 63:123-128.

30. Schuit, F.C. 1996. Factors determining the glucose sensitivity and glucose responsiveness of pancreatic beta cells. Horm. Res. 46:99-106.

31. Klinteberg, K.A., Karlsson, S., and Ahren, B. 1996. Signaling mechanisms underlying the insulinotropic effect of pituitary adenylate cyclase-activating polypeptide in HIT-T15 cells. Endocrinology. 137:2791-2798.

32. Davalli, A.M., et al. 1999. Insulin and intracellular calcium responsiveness to glucagon-like peptide-1 and pituitary adenylate cyclase-activating peptide by dispersed adult porcine islet cells. Transplantation. 67:174-176

33. Wei, Y., and Mojsov, S. 1996. Tissue specific expression of different human receptor types for pituitary adenylate cyclase activating polypeptide and vasoactive intestinal polypeptide: implications for their role in human physiology. J. Neuroendocrinol. 8:811-817.

34. Nakata, M., Shioda, S., Oka, Y., Maruyama, I., and Yada, T. 1999. Insulinotropin PACAP potentiates insulin-stimulated glucose uptake in 3T3 L1 cells. Peptides. 20:943-948.

35. Sekiguchi, Y., Kasai, K., Hasegawa, K., Suzuki, Y., and Shimoda, S. 1994. Glycogenolytic activity of pituitary adenylate cyclase activating polypeptide (PACAP) in vivo and in vitro. Life Sci. 55:1219-1228.

36. Yokota, C., Kawai, K., Ohashi, S., Watanabe, Y., and Yamashita, K. 1995. PACAP stimulates glucose output from the perfused rat liver. Peptides. 16:55-60.

37. Filipsson, K., Holst, J.J., and Ahrén, B. 1999. PACAP contributes to insulin secretion induced by gastric glucose gavage in mice. Diabetologia. 42(Suppl. 1):A40. (Abstr.)

38. Ahren, B. 1999. Regulation of insulin secretion by nerves and neuropeptides. Ann. Acad. Med. Singapore. 28:99-104.

39. Tornoe, K., Hannibal, J., Fahrenkrug, J., and Holst, J.J. 1997. PACAP-(138) as neurotransmitter in pig pancreas: receptor activation revealed by the antagonist PACAP-(6-38). Am. J. Physiol. 273:G436-G446. 